Volume 1, Issue 1, pp 105-117

Copyright @2021, Eva Pomeroy et al. https://doi.org/10.47061/jabsc.v1i1.676

ISSN 2767-6021

www.jabsc.org

\title{
In the Making
}

\section{Action Research from a Social Field Perspective}

\author{
Eva Pomeroy \\ Presencing Institute \\ pomeroy@presencing.com \\ Lukas Herrmann \\ Heidelberg University \\ Lukasherrmann@posteo.de \\ Sebastian Jung \\ Como Consult $\mathrm{GmbH}$ \\ Sebastian.Jung@como-consult.de
}

\author{
Els Laenens \\ University of Antwerp \\ els.laenens@uantwerpen.be \\ Laura Pastorini \\ Presencing Institute \\ pastorini@presencing.com \\ Angelique Ruiter \\ The Hague University of Applied Sciences \\ c.a.ruiter@gmail.com
}

\section{Our Intention}

We write this piece to share our discovery process as action researchers in an emergent change initiative. In particular, we want to explore and share the realization that we needed to expand our research framework mid-process in order to fully serve the transformational intention of the initiative and the research itself. The framework we need is one that both serves awareness-based action in emergent processes and generates widely applicable knowledge; that integrates a variety of perspectives on social phenomena (first-, second-, and third-person); and that aims to bring systematic inquiry both to the observable 
phenomena and the deeper underlying dimensions. The approach requires us to make visible our assumptions and to integrate and validate different epistemologies, including relational, intuitive, and aesthetic knowing. As such, the approach to research we suggest here can be thought of as an epistemological framework itself.

Our position surfaces from our recent experience as a team of embedded action researchers in an emergent change initiative called GAIA-Global Activation of Intention and Action-hosted by the Presencing Institute between March and June 2020. GAIA emerged during and in response to the COVID 19 global pandemic and associated lockdown. It aimed to bring together virtually a global community to bear witness to the current moment as a way to mobilize social change action (https://www.presencing.org/news/news/gaia-essentials). The GAIA initiative was based on Theory U (Scharmer, 2016, 2018a; Scharmer \& Kaufer, 2013), a framework and methodology explicit in its intention to build capacity for leading transformative social change through awareness-based tools and approaches. GAIA, then, can be considered an awareness-based systems change initiative.

The work described here takes place under the broad umbrella of action research and reflects its key properties. Describing the nature of action research, Bradbury (2015) states,

Action research is emergent and developmental. It concerns practical issues and human flourishing. Its modality is primarily participative and democratic, working with participants and toward knowledge in action. (p. 1)

All of these characteristics describe and shape our work. Further, we assumed a social field perspective. We consider the social field to be, "the entirety of the social system with an emphasis on the source conditions that give rise to patterns of thinking, conversing, and organizing, which in turn produce practical results" (Scharmer, Pomeroy \& Kaufer, 2021, p.5). The social field perspective rests on a number of assumptions. First, a social field perspective considers both the visible aspects of a social system and the less visible aspects, i.e., the inner or deeper dimensions of the system. The implication of this stance is that a social field cannot be known without the integration of first-, second-, and third-person perspectives of the system. First-person perspective relates to the individual experience in and of the social field, second-person to the intersubjective, shared experience, and third-person to what can be known about the social field through external observation. The second assumption is that there are layers of phenomena shaping the field. Observable social phenomena are shaped by interpersonal and organizational dynamics, patterns of organizing, and paradigms of thought. Underneath these, and giving rise to them, is individual and collective consciousness, also referred to as Source (Scharmer, 2016). The third assumption is that the social field functions as a living entity, continuously co-creating its reality-in-context. In other words, social fields are emergent (Goldstein, 1999). These assumptions have implications for a social field research 
methodology, and shape the research intention, the nature of data sought, the methods used to collect that data, and the processes for analysis and sensemaking.

One key aspect of a social field approach to action research is the embedded nature of the research and the researchers. All members of the research team hold a variety of roles in relation to the initiative, representing a particular positionality related to the Presencing Institute. The roles range from core team member to language track leader to members of affiliated communities, such as the Social Presencing Theater and Social Field Research communities. In addition, we all took part in the initiative as participants. Deep familiarity with an experience has been seen as a benefit of embedded research elsewhere, reducing the likelihood that the researchers misinterpret local phenomena and increasing the likelihood of forming strong relationships that support the research process (Rowley, 2014). However, that familiarity and closeness can be viewed as a limitation as internal researchers have a vested interest in the organization and existing relationships within it, risking the possibility for codependency or even coercion (Wong, 2009). As social field researchers seeking to understand the interior experience as well as the observable elements of the initiative, it was essential for us to move into the experience as participants in order to bring in our own first-person experience as data. We aim to counter the limitations cited above by being transparent and self-reflective about our process, 'bending the beam' of our attention back on ourselves and the research process here.

We believe that we will increasingly find ourselves in globally disrupted situations - such as the pandemic context that gave rise to GAIA — that do not afford lengthy periods of planning time before action is needed. Research needs to keep pace with our current disrupted and unpredictable global context in order to be useful to the individuals and settings where it takes place-a key principle of action research (Bradbury, 2015; Coughlan \& Abraham, 2018; Stringer 2014). Further, research needs to honour multiple forms of knowing if it is genuine in its effort to accurately represent the 'whole' of experience as a basis for social change. Temper, McGarry \& Weber (2019) observe, "The role of science and knowledge production is at a crossroads, as societal transformation calls for challenging dominant forms of knowledge production that have contributed to marginalizing other ways of knowing" (para 1). From a social field perspective, a new epistemological framework is needed in order to address the root causes of current disruption, namely, the dynamics and source conditions from which social systems originate and evolve.

\section{The GAIA Context}

The Theory U process, on which GAIA is based, is built upon more than twenty years of action research at MIT. The intention of this work has been to build leadership capacity amongst individuals, teams, organizations, and large systems in order to address the root causes of social, environmental, and 
spiritual challenges (https://www.presencing.org/aboutus/theory-u). Theory U emphasizes self- and ecosystem awareness, attention to quality of listening and attending, consciousness, and action for societal transformation. In previous research, outcomes described by participants in a Theory U-based program included increased sense of self and clarity of purpose, increased capacity for perspective taking and deep listening, more inclusive decision-making, and greater willingness to step into new action, referred to as action confidence (Pomeroy \& Oliver, 2021). While GAIA itself was not a developmental program, it drew on practices established in programmatic work to operate as a 'holding space' for the moment and the community, with an explicit intention to support transformative learning and action.

The central feature of the GAIA process was a series of 90-minute bi-weekly online gatherings hosted on Zoom, supported by optional self-organizing smallgroup processes. Sessions included conceptual framing, guest speakers, smallgroup dialogue, and contemplative practices, including embodiment exercises. Over the fourteen-week duration of GAIA, thirteen thousand people from 77 countries participated. While the bi-weekly structure was determined at the outset, the specific form of the sessions took shape as the initiative progressed, so the process was iterative, evolving, and emergent.

The research was initiated by the Presencing Institute to support the wider intention of GAIA. This means the initiative and research rest on the same assumptions that underlie the initiative and that have been stated by Scharmer (2018b) as follows:

You cannot understand a system unless you change it (Kurt Lewin).

You cannot change a system unless you transform consciousness.

You cannot transform consciousness unless the system senses and sees itself. (para 16)

The primary contribution of the research was in relation to the third of the points above. Our role as a research team was to provide rapid feedback to the global community in order 'to help the system see and sense itself'. We designed data collection methods to provide a structure for reflection that supported participants' capacity to understand (i.e., see and sense) their individual experience, while data sharing aimed to mirror back the collective experience of which they were a part.

\section{The Research Process: Social Field Research in the Making}

The research process was iterative. It began with a short, open-answer survey and evolved to include online focus groups as a space for deeper reflection and dialogue. Three online surveys were used, one at the beginning, middle, and end of the initiative. Four focus groups were formed, two meeting monthly and two 
bi-monthly. In addition to surveys and focus groups-more traditional methods of data collection-we also explored emergent methodologies that aimed to access other forms of knowing, such as intuitive, sensory, and aesthetic forms. Doing so is in keeping with a social field approach and its interest in the deeper layers of collective experience. These layers underlie observable behaviour but cannot, from an external perspective, be observed and so we need to engage other forms of perceiving and knowing to access them.

\section{Second-Person Research}

There are two aspects of the inquiry into these deeper layers that shape the epistemological framework we are suggesting here. First, the inquiry needs to happen from inside the phenomenon. By definition, it simply can't be observed from the outside. That means we have to draw on first- and second-person experiences. First-person perspective is important, as it yields personal experience with and within the social field as relevant data. In addition, as researchers we can cultivate our capacity to pay attention to what is happening in the field as a way of using first-person perception as a gateway to understanding collective experience. It is this sense of the first-person perspective that we drew on for our collective, second-person inquiry. Reflecting Torbert's (2004) conceptualization, we consider second-person research to be that which happens in holding spaces where groups engage intentionally for the purpose of sense-making. Second-person knowing has probably been best described through Bohm's concept of dialogue, where collective engagement, "make[s] possible a flow of meaning for the whole group, out of which may emerge some new understanding" (Bohm, 1996, p. 6). The potential contribution of second-person inquiry to generate knowledge has been seriously underattended in research. Few methodologies for it have been well-established. We aimed to access second-person knowing in both the focus groups, which were designed to be 'holding spaces' for dialogue, and by consciously integrating second-person inquiry into our sense-making process as a research team.

\section{Multiple Ways of Knowing}

The second key aspect of making visible in collective experience that which is not, is that it requires experimentation with methods for accessing sensorial, intuitive, and aesthetic knowing. De Sousa Santos (2018) states, "[k]nowledge is not possible without experience, and experience is inconceivable without the senses and feelings they arouse in us" (p. 165). While methods for inquiring into observable, measurable phenomena abound, those that aim to access the less cognitive-focused aspects of experience are disparate and often nascent. Our own work in this area can be thought of as an experiment in developing a methodology for accessing and inquiring into the less visible aspects of collective phenomena. 


\section{A Methodological Prototype}

To this end, we designed a reflective journaling and dialogue process. First, we shared data from focus groups, personal experience, and analysis of survey findings. Next, we engaged with a sequence of questions designed to access our feeling-knowing ("what is most surprising in what we are hearing and experiencing?', 'what most touched me?', 'what is the emotional tone of the experience, for others and for myself?') and our intuitive knowing ('if the experience/emerging community was a living being, what would it look and feel like?', 'what is the generative source that allows this being to thrive?', 'what limiting factors prevent it from developing further?'). We responded to the journaling questions individually, then shared reflections in dialogue, making meaning of our reflection-findings together. This process was developed over the course of three iterations, eventually integrating a component of embodied practice to sense into the collective experience by representing it with body shapes.

The nature of the data these experiences surfaced tended to relate to the social field as a whole. For example, we first engaged in this process using data from the second survey as a basis for our sensing. After sharing our analysis of the survey responses, we shifted to the journaling process described above. What surfaced from the exercise and dialogue that followed was the story of a social field maturing. The word 'maturing' emerged in relation to the collective and resonated with us as a description of what was happening on a field level. This maturing process was reflected in comments that seemed more complex and differentiated than those in the earlier survey, as well as more self-reflective. This was true across several broad themes in the data. For example, in relation to the theme 'community' initial comments were often more uni-dimensional, for example expressing appreciation for finding others who were like-minded:

[I experienced] The power of being part of a community-around the world-who are interested in using this disruption to reimagine the world.

While the general sentiment and tone remained the same, many comments in the second survey seemed to reflect a more nuanced view, for example differentiating the personal experience from the collective one and integrating the two:

I want to be part of creating a new social order, based on what I (and many others) have seen and heard. My contribution may be small, and I want to make it in solidarity with others.

Being part of GAIA Journey gives me grounding and a sense of being part of something bigger in terms of purpose (something that gives life at the same time to my own purpose in life).

A similar process of maturing was perceived in relation to comments around the theme 'holding contradiction'. An early comment reflecting this was: 


\section{[I feel] Confused but hopeful.} nuance:

...while a later comment unpacks the sense of contradiction with significant

I feel shaken to my roots, and that sometimes scares me, and I feel insecure, unstable. But I am also determined to be a bit more sincere in my whole being present. And at the same time I feel calm and peaceful, strong and easy going to see what is happening.

While we have used comments (observable data) here to illustrate our point, it is important to note that the 'finding' that the social field had matured surfaced from the journaling exercise and dialogue. It is our feeling that the sensing processes surfaced aspects of the collective experience that resonated as true reflections of it, but that were not directly stated in any of the data. Further, this change in the field may not have become apparent without the process. One of the most challenging aspects of the research has been to integrate and share the data from the sensing process. While the data 'rings true', few models exist to integrate collectively sourced, intuitive, sensorial data into research.

\section{Research in Action: Closing the Feedback Loop}

The point of the research was to help the community see and sense itself as part of the transformative learning process, i.e., to serve action in an emergent process. This happened by feeding data back to the participant community during live online gatherings. Here we see the integration of first-, second-, and third-person inquiry as well as the iterative nature of action research. After collecting survey data (third-person inquiry) and analyzing that data both traditionally and through our sensing process (second-person inquiry), we selected aspects of the data to share in focus groups to explore their resonance (first- and second-person inquiry). Working with the GAIA media team, we created a compilation of video clips from the recorded focus group calls to reflect back to the community some of the key themes emerging from these conversations. The video clip was then shown in plenary during the online gathering in an effort to mirror back to the community their collective experience.
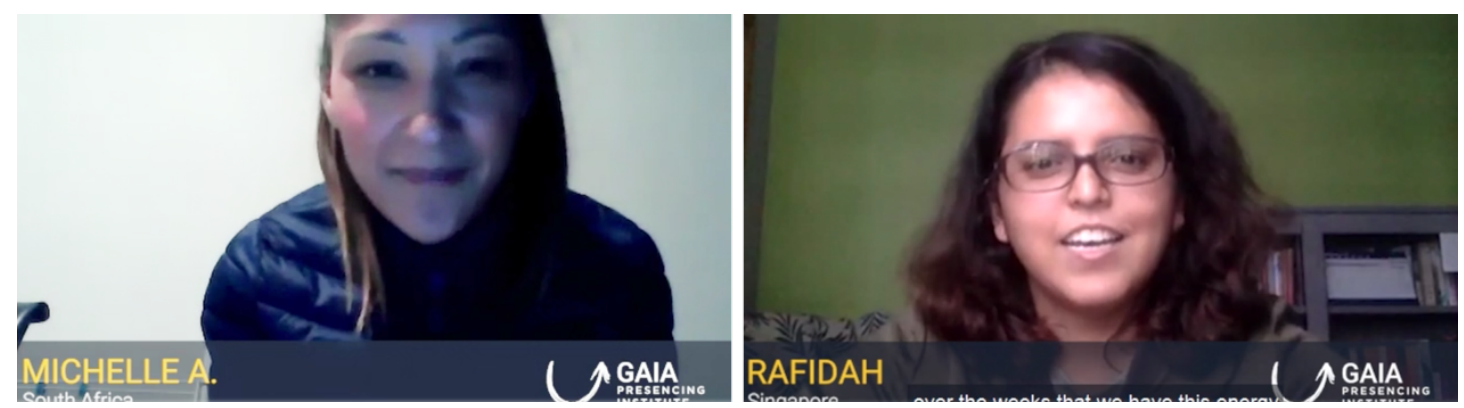

Figure 1: Two community members who contributed to focus group comments shared in GAIA plenary. Full compilation video: https://vimeo.com/425765149 
The video clip then surfaced feedback from participants in the online session as they expressed the resonance they felt with different themes shared in the video in the 'chat' function of the zoom call. Some of the comments in response to the video above were:

the idea "we are not alone" resonates so deeply with me we are not alone with laughter made me burst into tears. It's not me to feel this way.

Thank you for the beautiful sharing of your hearts which touched mine and opened it further!! We are not alone...thank heavens... and I do.

I really need to hear that there is still a core of common humanity in the world.

seeing, sensing, feeling yet a sense of inadequate strategy to create change

We realize that comments in the call chat discussion likely don't capture the full range of responses to the video as people may be reticent to share more critical comments in a public chat. However, the comments people do share give an indication of which themes surfacing in the focus groups have the most resonance for the larger community. The resonance then added a further layer of data, shaping our inquiry, for example, motivating us to ask a question in a subsequent survey to explore the role of interconnectedness ('we are not alone') in the overall experience of the initiative.

Bradbury (2015) states, "action researchers draw on and contribute to an ever-increasing repertoire of experiential practices at personal, interpersonal, and/or collective levels, allowing us to address complex problems while also giving attention to coordinating needed action" (p. 1). Our research began with traditional methodologies and, over time, led us to experiment with emerging methodologies as well, all in an effort to support action, i.e., contributing to the transformative change process by mirroring the system-in-its-process back to itself.

\section{Questions for an Emerging Framework}

Our need for an integrated research framework arose in the midst of our experience as embedded action researchers in a highly emergent context. Our aim throughout was for our inquiry to serve action in this specific context, while simultaneously generating more widely applicable knowledge. Building a research framework was not our original focus. Rather, the need surfaced as we tried to accurately reflect the collective experience back to the community as the initiative unfolded. We drew considerably on traditional data collection and analysis methods. These more cognitive-focused forms of inquiry and knowing made a significant contribution to our understanding of the collective experience. However, they were not enough. As Anderson and Braud (2011) observe, "so 
often our research methods fall flat before the fullness and extraordinary experience of being human day-to-day" (p. 3). So, while traditional methodologies helped us to 'see' the collective experience, they were of less service in our efforts to 'sense' it. To do so required us to access the less visible, felt aspects of the experience and to do that required new methods that drew on our sensory, intuitive, and aesthetic knowing. Further, in exploring collective experience, we needed to privilege collective inquiry and so designed methods based on a secondperson perspective.

Key questions surfaced that, pursued, will help to shape the epistemological framework that has begun to emerge for us through this work.

1. How can we further develop second-person research? What is the place of collective sense-making in research? The second-person space is a particularly interesting aspect of our research, as it is little addressed elsewhere. Operating from a social field perspective, we pay special attention to the quality of relating in the holding space, consciously working to cultivate safety, openness and dialogue, and incorporating contemplative practices to do so. What are the implications of this approach for research? What kind of conceptual and practical frameworks are needed to further develop second-person research? What is the nature of the data collected in these holding spaces, and what does it serve?

2. How can we further integrate and render valid intuitive, aesthetic, and embodied data? How can we further evolve emerging methodologies related to sensorial knowing and integrate these with more established approaches to research? Holistic knowledge systems have long been a part of Indigenous scholarship (Cajete, 2005; Goodchild, 2021; Kimmerer, 2013; Kovach, 2007) and aesthetic and embodied forms of knowing are increasingly acknowledged elsewhere in academia (Ignatow, 2007; Shrivastava, Schumacher, Wasieliski \& Tasic, 2017; Sutherland \& Jelinek, 2015). About one month into the initiative, the research team added into the data analysis the process described above (reflective journaling and dialogue process) in order to access more intuitive, emotional-relational, and embodied ways of knowing. The process represents our effort to bring systematic inquiry to the deeper, less cognitive-centric levels of knowing. When we shared the results of our collective sensing, it seemed to have much resonance with participants, as gauged by comments in the zoom chat and personal communication 
afterward. Still, it remains difficult to 'fit' that data into the research findings or even to write about it. What

frameworks help ease the integration of different forms of knowing into our accounts of phenomena? What methods would render the data 'trustworthy' and thus easier to include?

3. How do we generate data that serves rigour and relevance in emergent processes? Levin (2012) argues that, "action research cannot contribute to the social science debate unless its findings are considered trustworthy and relevant" (p. 134). We believe there is tremendous potential to generate valuable, useful, and generalizable knowledge about social phenomena through the research effort to understand and support it as it unfolds. Our aim was to collect and process high-quality data AND to share our findings rapidly so that it could be useful to the initiative and the community. In action research, rigour, "is based on checks to ensure that the outcomes of research are trustworthy" (Stringer, 2014, p. 92). Some of our practices reflected the rigour more characteristic of traditional research approaches. For example, our process of "checks" in the analysis of survey data was to have at least two team members review responses to a survey question, organize the data into themes and then come together to synthesize our findings and make sense of the data as a whole. Here the integration of second-person inquiry - sense-makingserves a dual purpose. It adds rigour to the process through its "check" on individual analyses, but it also has the potential to generate new understanding by deepening the meaning-making through collective inquiry, questioning, and dialogue around the findings.

The relevance of the research lay largely with its capacity to serve an emergent process as it emerged. One challenge here was the time delay between collecting data and feeding the findings back to the community. Even though the process of data collection, analysis, and feedback felt like a "sprint" for the team, there was a delay for two to four weeks between data collection and feedback to the community, running the risk that the feedback could be 'out of step' with the collective experience. In one strand of the initiative - a Spanish-language version of the process - facilitators experimented with interactive polling software (mentimeter) to share immediate raw data from participants about their experience the moment it was generated. The benefit of this approach is that it removes the issue of the time-lapse and involves 
the community in sense-making, but it does require the community itself to process and make sense of a large amount of data within a limited timeframe.

We are left with several questions here. What data collection and feedback processes best serve the intention to help a system see and sense itself? Put more generally, what are the methods that best serve action in an emergent process? How can these best be developed so that they simultaneously generate knowledge applicable beyond the specific initiative? How can we evolve methods that reconcile the need for rapid feedback with the need for quality data-both cognitive-relational and sensory-intuitive?

\section{Conclusion}

Our intention with this piece is to highlight, through our experience as embedded action researchers in an emergent change process, the need for an integrated research framework. The framework we found we needed is one that both serves awareness-based action and generates widely applicable knowledge; that integrates first-, second-, and third-person perspectives on social phenomena; and that aims to bring systematic inquiry both to observable phenomena and to the less visible dimensions that underlie it. From a social field perspective, all activity undertaken under the banner of 'research' is done in service of social transformation-making the deeper structures of systems visible in order to transform them.

The methods aligned with this research framework evolve in the process of using them. Early precedence for this kind of approach to methodological development can be found in the work of Kurt Lewin, considered by many the founder of social psychology. Using the metaphor of resource extraction and highway construction, reflecting the era in which he was writing, he describes the process of developing a new domain of study and understanding:

... small paths are pushed out through the unknown; with simple and primitive instruments, measurements are made; much is left to assumption and to lucky intuition. Slowly certain paths are widened; guess and luck are gradually replaced by experience and systematic exploration with more elaborate instruments... (Lewin, 1951, p.3)

The development of appropriate research methodologies is itself an iterative, experiential learning endeavour. Methodology must develop in tandem with the work in order to develop an understanding that is a. accurate and whole, and b. useful in practical, actionable terms. Our current context of disruption makes the need for methodologies that both serve emergent phenomena and generate knowledge from it all the more pressing. In this piece, we hope to have surfaced questions that stimulate consideration, critique, debate and, more than anything 
else, future action that evolves the field of social field research to support awareness-based systems change.

\section{References}

Anderson, R. \& Braud, W. (2011). Transforming self and others through research: Transpersonal research methods and skills for the human sciences and humanities. State University of New York Press.

Bohm, D. (1996). On Dialogue. Routledge.

Bradbury-Huang, H. (2010). What is good action research? Action Research, 8(1), 93-109. https://doi.org/10.1177/1476750310362435

Bradbury, H. (2015). The SAGE Handbook of Action Research. SAGE Publications Ltd. doi: $10.4135 / 9781473921290$

Cajete, G. A (2005). American Indian epistemologies. New Directions for Student Services, (109), 69-78. https://doi.org/10.1002/ss.155

De Sousa Santos, B. (2018). The end of the cognitive empire: The coming of age of epistemologies of the south. Duke University Press.

Goldstein, G. (1999). Emergence as a construct: History and issues. Emergence, 1(1), 4972. https://doi.org/10.1207/s15327000em0101_4

Goodchild, M. (2021). Relational systems thinking: That's how change is going to come, from our Earth Mother. Journal of Awareness-Based Systems Change, 1(1). https://doi.org/10.47061/jabsc.v1i1.577

Ignatow, G. (2007). Theories of embodied knowledge: new directions for cultural and cognitive sociology? Journal for the Theory of Social Behaviour, 37(2), 115-135.

Kimmerer, R. W. (2013). Braiding Sweetgrass. Milkweed Editions.

Kovach, M. (2015). Emerging from the margins: Indigenous methodologies. In S. Strega \& L. Brown (Eds.), Research as resistance Critical, indigenous, \& anti-oppressive approaches (pp. 19-36). Canadian Scholars Press.

Levin, M. (2012). Academic integrity in action research. Action Research, 10(20), 133-149. https://doi.org/10.1177/1476750312445034

Lewin, K. (1951). Field theory in social science. Harper \& Row.

Pomeroy, E. \& Oliver, K. (2021). Action confidence as an indicator of transformative change. Journal of Transformative Education, 19(1), 68-86. doi:10.1177/1541344620940815

Rowley, H. (2014). Going beyond procedure: Engaging with the ethical complexities of being an embedded researcher. Management in Education, 28(1), 19-24. doi:10.1177/0892020613510119

Scharmer, C. O. (2016). Theory U: Learning from the future as it emerges. (2nd ed.). Berrett-Koehler Publishers.

Scharmer, C. O. (2018a). The essentials of Theory U: Core principles and applications. Berrett-Koehler.

Scharmer, C. O. (2018b). Three stages of global movement building: Soil, seed, \& ecosystem activation. Field of the Future Blog. https://medium.com/presencing-instituteblog/three-stages-of-global-movement-building-soil-seed-eco-system-activationa383a6d $3 f c 8 b$ 
Scharmer, C. O., \& Kaufer, K. (2013). Leading from the emerging future: From ego-system to eco-system economies. Berrett-Koehler Publishers.

Scharmer, O., Pomeroy, E. \& Kaufer, K. (2021 - forthcoming). Awareness-Based Action Research: Making Systems Sense and See Themselves. In D. Burns, J. Howard, J. and S.M. Ospina (Eds.) The SAGE Handbook of Participatory Research and Enquiry. SAGE Publications Ltd.

Shrivastava, P., Schumacher, G. Wasieliski, D. \& Tasic, M. (2017). Aesthetic Rationality in Organizations: Toward Developing a Sensitivity for Sustainability. The Journal of Applied Behavioral Science, 53(3), 369-411. DOI: 10.1177/0021886317697971

Stringer, E. T. (2014). Action Research, 4th ed. SAGE Publications.

Sutherland, I., Jelinek, J. (2015). From Experiential Learning to Aesthetic Knowing: The Arts in Leadership Development. Advances in Developing Human Resources, 17(3), 289-306. doi:10.1177/1523422315587894

Temper, L., McGarry, D., \& Weber, L. (2019). From academic to political rigour: insights from the 'tarot' of transgressive research. Ecological Economics, 164. https://doi.org/10.1016/j.ecolecon.2019.106379

Torbert, B. (2004). Action Inquiry: The secret of timely and transforming leadership. Berrett-Koehler.

Wong, E. (2009). Tales from the frontline: The experiences of early childhood practitioners working with an 'embedded' research team. Evaluation and Program Planning, 32(2), 99-108. https://doi.org/10.1016/j.evalprogplan.2008.10.003 